\title{
Compressibility of Ir-Os alloys under high pressure
}

Kirill V. Yusenko ${ }^{1, *}$, Elena Bykova ${ }^{2,3}$, Maxim Bykov $^{4}$, Sergey A. Gromilov ${ }^{5,6}$, Alexander V. Kurnosov ${ }^{3}$, Clemens Prescher ${ }^{7}$, Vitali B. Prakapenka ${ }^{7}$, Michael Hanfland $^{8}$, Sander van Smaalen ${ }^{4}$, Serena Margadonna ${ }^{1}$, and Leonid S.

Dubrovinsky ${ }^{3}$

${ }^{1}$ Department of Chemistry, Center for Materials Science and Nanotechnology, University of Oslo, PO Box 1033 Blindern, NO-0315 Oslo, Norway

${ }^{2}$ Materialphysik und Technologie, Lehrstuhl für Kristallographie, Physikalisches Institut, Universität Bayreuth, D-95440 Bayreuth, Germany ${ }^{3}$ Bayerisches Geoinstitut, Universität Bayreuth, D-95440 Bayreuth, Germany

${ }^{4}$ Laboratory of Crystallography, University of Bayreuth, D-95440 Bayreuth, Germany

${ }^{5}$ Department of Physics, Novosibirsk State University, Pirogova str. 2, 630090 Novosibirsk, Russia

${ }^{6}$ Department of Crystal Chemistry, Nikolaev Institute of Inorganic Chemistry, Lavrentiev ave. 3, 630090 Novosibirsk, Russia

${ }^{7}$ Center for Advanced Radiation Sources, University of Chicago, Chicago, Illinois 60637, USA

${ }^{8}$ European Synchrotron Radiation Facility, Polygone Scientifique Louis Neel, 6 rue Jules Horowitz, 38000, Grenoble, France 
* Corresponding author: Department of Chemistry, Center for Materials Science and Nanotechnology, University of Oslo, PO Box 1033 Blindern, NO-0315 Oslo, Norway. Tel: +4722855591, Fax: +4722855591, e-mail: kirill.yusenko@smn.uio.no

Several $f c c$ - and $h c p$-structured Ir-Os alloys were prepared from singlesource precursors in hydrogen atmosphere at $873 \mathrm{~K}$. Their atomic volumes measured at ambient conditions using powder x-ray diffraction follow nearly linear dependence as a function of composition. Alloys have been studied up to $30 \mathrm{GPa}$ at room temperature by means of synchrotron-based x-ray powder diffraction in diamond anvil cells. Their bulk moduli increase with increasing osmium content and show a deviation from linearity. Bulk modulus of hcp$\mathrm{Ir}_{0.20} \mathrm{Os}_{0.80}$ is identical to that of pure Os $(411 \mathrm{GPa})$ within experimental errors. Peculiarities on $f c c$ - $\operatorname{Ir}_{0.80} \mathrm{Os}_{0.20}$ compressibility curve indicate possible changes of its electronic properties at $\sim 20 \mathrm{GPa}$.

Keywords: high-pressure, alloys, iridium, osmium 


\section{Introduction}

Heavy transition metals such as Ta, W, Re, Os and Ir have high densities and extremely high melting points, as well as exceptional mechanical, thermal and chemical stabilities. Their very low compressibilities (bulk moduli are comparable with those of diamond) make these metals essential subjects for high-pressure studies. Phase stabilities, compressibility and equations of state of the pure platinum group metals (PGM) $\mathrm{Rh}, \mathrm{Ru}, \mathrm{Os}$ and $\mathrm{Pd}$ have been investigated under high pressures up to $75 \mathrm{GPa}$, whereas Pt and Re have been studied at multi-megabar pressures up to 304 and $640 \mathrm{GPa}$, respectively [1-3]. For PGM (except Ir) and Re no high-temperature and high-pressure structural transformations were reported. Cerenius et al. [4] reported formation of 14layered superstructure in Ir above $\sim 59 \mathrm{GPa}$, but it was questioned by theoretical calculations [5]. There are several controversial reports regarding the existence of an isostructural electronic topological transition in Os below $70 \mathrm{GPa}$ [6-8].

Up to now, experimental data for compressibility, hardness, and phase stability for PGM solid solutions were unavailable. Only sporadic investigations have been performed for PGM-based binary systems with non-PGMs (mainly Ir-Hf system) $[9,10]$. The detailed information on high-pressure hightemperature behaviour and hardness of $\mathrm{PGM}-\mathrm{Ru}, \mathrm{PGM}-\mathrm{Re}$, and PGM-Os (especially fcc-hcp-based systems) solid solutions helps in a search of materials

with promising mechanical and chemical properties [11]. Recently, [12] two 
ordered phases, namely $\mathrm{Ir}_{8} \mathrm{Os}$ and $\mathrm{IrOs}_{5}$, stable at low temperature were predicted by the high-throughput calculations. Since ordered phenomena in PGM-based binary systems have not yet been observed experimentally, predicted phases should be evaluated with a great precaution. Detailed highpressure experiments may reveal experimental conditions for stabilizing ordered and/or metastable binaries. An application of high pressure and high temperature to alloys between low compressible metals may induce structural changes unknown for pure species, how it has been observed for instance for Sn-based alloys under high-pressure [13].

The binary $\mathrm{Ir}-\mathrm{Os}$ system has been investigated in detail at ambient pressure up to the melting point of osmium which is reported to be $3306 \mathrm{~K}$ [1517]. The corresponding peritectic equilibrium phase diagram has a nearly vertical miscibility gap in the solidus part between face centred cubic $(f c c)$ and hexagonal closed packed ( $h c p$ ) phases with maximal solubility of Ir in Os and Os in Ir at $1273 \mathrm{~K}$ estimated as 42 and 37 at.\% respectively and peritectic temperature determined as $2933 \mathrm{~K}$ (Fig. 1). Phase stability in the Ir-Os system has also importance for the genesis of the natural $\mathrm{Ir}-\mathrm{Os}-\mathrm{Ru}$ and other PGMbased metallic minerals which show complex nature and non-equilibrium character at ambient conditions due to their formation under high-pressure from the poly-component melt in Earth mantle [18-20]. Os-rich phases are particularly interesting due to the significance of Os as a possible model of iron behaviour in the Earth's core [21]. 
The goal of present work is to improve knowledge about phase stability and compressibility under high pressure of binary $\mathrm{Ir}-\mathrm{Os}$ system. Presynthesized homogeneous Ir-Os solid solutions in a wide range of concentrations were systematically investigated under high temperature at ambient pressure and high pressure at room temperature.

\section{Experimental details}

Ir-Os solid solutions were prepared using single-source precursors strategy based on our previous findings $[22,23] .\left(\mathrm{NH}_{4}\right)_{2}\left[\operatorname{Ir}_{x} \mathrm{Os}_{1-x} \mathrm{Cl}_{6}\right]$ precursors were crystallized from concentrated water solutions of $\mathrm{K}_{2}\left[\mathrm{OsCl}_{6}\right]$ and $\left(\mathrm{NH}_{4}\right)_{2}\left[\mathrm{IrCl}_{6}\right]$ (both $99.9 \%$ purity, abcr $\mathrm{GmbH} \& \mathrm{Co} . \mathrm{KG}$ ) by adding excess of saturated at room temperature $\mathrm{NH}_{4} \mathrm{Cl}$ (ACS reagent of $99.5 \%$, Sigma-Aldrich) solution in distilled water. Brown-black precipitates were filtered out, washed with $1 \mathrm{M}$ water solution of $\mathrm{NH}_{4} \mathrm{Cl}$ and acetone. All $\mathrm{Ir}_{x} \mathrm{Os}_{1-x}$ samples were prepared by thermal decomposition of crystalline single-source precursors $\left(\mathrm{NH}_{4}\right)_{2}\left[\operatorname{Ir}_{x} \mathrm{Os}_{1-x} \mathrm{Cl}_{6}\right]$ in $10-$ vol. $\%-\mathrm{H}_{2} / 90$-vol. $\%-\mathrm{N}_{2}$ (compressed gas mixture, AGA) stream during 0.5 $\mathrm{h}$ at $873 \mathrm{~K}$ with further cooling to room temperature during $10 \mathrm{~h}$. Samples were also annealed in evacuated quartz ampoules at $1273 \mathrm{~K}$ during $48 \mathrm{~h}$ and quenched in ice-cold water to proof their temperature stability. Phase composition and cell parameters of synthetized and annealed at high-temperature samples was proved by in house powder $\mathrm{x}$-ray diffraction (PXRD) using an ARL X'TRA 
diffractometer $(\mathrm{CuK \alpha}$-radiation, Ni-filter, position sensitive detectors, BraggBrentano reflection geometry, $2 \Theta=5-100^{\circ}, \Delta 2 \Theta=0.03^{\circ}, 10 \mathrm{~s} / \mathrm{step}$, room temperature). A polycrystalline sample was slightly ground with hexane using an agate mortar, and the resulting suspension was deposited on the polished side of a quartz sample holder, a smooth thin layer formed after drying. Silicon powder was taken as an external standard $\left(\mathrm{a}=5.4309 \AA\right.$, FWHM $\left.2 \Theta=0.1^{\circ}\right)$ for calibration of the zero-shift of the goniometer and instrumental line broadening. Only $f c c$ - and $h c p$-based alloys as well as their two-phase mixtures were found as products of different syntheses (Table 1). Diffraction lines show noticeable broadening corresponding to particle size about $100 \mathrm{~nm}$. Morphology and composition of resulting metallic powders were investigated using FEI Quanta 200 FEG-ESEM scanning electron microscope (SEM) equipped with EDAX EDS. Only iridium and osmium were found in all metallic samples, metallic composition has been obtained in 3-4 independent points and averaged.

High-pressure PXRD data for $h c p-\mathrm{Ir}_{0.20} \mathrm{Os}_{0.80}$ and $h c p-\mathrm{Ir}_{0.40} \mathrm{Os}_{0.60}$ were collected up to $25 \mathrm{GPa}$ and for $f c c-\mathrm{Ir}_{0.80} \mathrm{Os}_{0.20}$ up to $55 \mathrm{GPa}$ at room temperature at the ID-09A beam-line at the ESRF $(\lambda=0.4145 \AA$, MAR 555 flat panel detector, beam size $\left.10 \times 15 \mu \mathrm{m}^{2}\right)$. $h c p-\mathrm{Ir}_{0.55} \mathrm{Os}_{0.45}$ alloy has been investigated up to $30 \mathrm{GPa}$ at the 13-IDD beam-line at the APS $(\lambda=0.3100 \AA$, CCD MAR 165 detector, beam size $3 \times 3 \mu \mathrm{m}^{2}$ ). BX90 diamond anvil cells with $250 \mu \mathrm{m}$ or 120 $\mu \mathrm{m}$ culet size diamonds were employed [24]. Rhenium gaskets were preindented to thickness of about $20 \mu \mathrm{m}$ and holes with diameter of about half of 
diameter of culet size were drilled in the centre of the indentation. Hightemperature silicone oil (Dow Corning 200 ${ }^{\circledR}$ with viscosity $60000 \mathrm{cSt}$ at $25{ }^{\circ} \mathrm{C}$ from Sigma-Aldrich) was used as pressure-transmitting medium in experiments at ESRF, and neon (loaded at pressure $1.3 \mathrm{kbar}$ ) in experiment at APS. Pressure was determined using equation of state of gold [25] loaded in the pressure chamber as small piece of wire of $5 \mu \mathrm{m}$ diameter and about $10 \mu \mathrm{m}$ length, or as flake of compressed fine powder. For data analysis, two-dimensional images were first integrated to one dimensional intensities counts as a function of diffraction angle using the FIT2D software [26]. Unit cell parameters were refined using model-free full-profile refinement. Unit cell, background, and lineprofile parameters for sample and gold internal standard were refined simultaneously using JANA2006 software [27]. A typical least-square fit is shown in Fig. 2.

\section{Results and discussion}

\subsection{Phase composition of $\mathrm{Ir}-\mathrm{Os}$ alloys}

Seven $\operatorname{Ir}_{x} \mathrm{Os}_{1-x}$ samples with $x=0.80,0.65,0.60,0.55,0.50,0.40,0.20$ were synthesized. Four samples with $x<0.55$ have $h c p$ structure. $h c p-\operatorname{Ir}_{0.55} \mathrm{Os}_{0.45}$ and $h c p-\mathrm{Ir}_{0.40} \mathrm{Os}_{0.60}$ have compositions close to limiting stability regions of $f c c$ and $h c p$ phases, respectively (Fig. 1). $h c p$ - $\operatorname{Ir}_{0.50} \mathrm{Os}_{0.50}$ falls in the middle of miscibility 
gap between $f c c$ and $h c p$ phases on the experimental phase diagram [15]. Two samples with compositions $\operatorname{Ir}_{0.60} \mathrm{Os}_{0.40}$ and $\operatorname{Ir}_{0.65} \mathrm{Os}_{0.35}$ correspond to $f c c$ region of phase diagram (Fig. 1) but, according to PXRD, both are two-phase mixtures. The clear disagreement between phase composition of prepared solid solutions and existing experimental diagram can be explained by the metastable nature of phases synthesized from single-source precursors under relatively mild conditions (short heating at $873 \mathrm{~K}$ ). The elemental analysis suggests that chemical composition of alloys is defined by Os:Ir ratio in the starting water solutions of $\mathrm{K}_{2}\left[\mathrm{OsCl}_{6}\right]$ and $\left(\mathrm{NH}_{4}\right)_{2}\left[\mathrm{IrCl}_{6}\right]$. A possible presence of non-metals $(\mathrm{Cl}$, $\mathrm{N}, \mathrm{O}, \mathrm{H})$ or $\mathrm{K}$ was not detected by EDX as well as any admixtures such as metallic hydrides or chlorides were not detected by PXRD. Metallic composition for resulting metallic alloys obtained by EDX is shown in Table 1. SEM images reveal that alloys powders consist of octrahedrally shaped micrometer-scale porous conglomerates which inherit initial shape of precursor's crystals (Fig. 3). Conglomerates include smaller particles of various sizes.

\subsection{Atomic volumes of Ir-Os alloys: Composition dependence}

The atomic volume is defined as a ratio between the unit cell volume, $V$, and number of atoms per the unit cell, $Z(Z=2$ for $h c p$ and $Z=4$ for $f c c$ structures). According to Zen's law [30], the atomic volumes, $V / Z\left(\AA^{3} \cdot \operatorname{atom}^{-1}\right)$, 
for $h c p-f c c$ bimetallic alloys should follow nearly linear dependence on composition with a relatively small positive or negative deviation [31, 33]. Data for atomic volumes of several Ir-Os phases known in the literature [28, 29, 22] are summarized in Table 2. Cell parameters for a number of alloys investigated in [29] were obtained with relatively high errors which makes analysis of possible positive or negative deviations difficult. Data on samples investigated in the present study are presented in Table 1 and graphically in Fig. 4.

Previous experimental data for Ir-Os alloys have been obtained with relatively high experimental uncertainties, which makes $V / Z$-composition dependence based on the polynomial functions less reliable. The corresponding V/Z-composition dependence can be approximated linearly:

$$
V / Z\left(\AA^{3} \cdot \operatorname{atom}^{-1}\right)=14.157(6)-0.18(1) \cdot x_{\mathrm{Os}}
$$

where $x_{\mathrm{Os}}$ is atomic fraction of Os in the alloy. One can use this dependence to estimate the composition of Ir-Os phases with known unit cell parameters (Fig.4). That is especially relevant for two-phase samples where only the initial total composition is known. Detailed analysis of as-synthetized and annealed two-phase samples outsteps current study and will be presented later. 


\subsection{High-temperature annealing of synthesized the $\mathrm{Ir}-\mathrm{Os}$ alloys at ambient}

\section{pressure}

Three $h c p-\mathrm{Ir}_{0.45} \mathrm{Os}_{0.55}, h c p-\mathrm{Ir}_{0.50} \mathrm{Os}_{0.50}$, and $h c p-\mathrm{Ir}_{0.40} \mathrm{Os}_{0.60}$ samples appeared to be single phase in two-phase region of the equilibrium phase diagram which may be a sign for their metastable nature. Three $f c c-\mathrm{Ir}_{0.80} \mathrm{Os}_{0.20}, h c p-\mathrm{Ir}_{0.55} \mathrm{Os}_{0.45}$, and $h c p-\mathrm{Ir}_{0.40} \mathrm{Os}_{0.60}$ single-phase samples were annealed at $1273 \mathrm{~K}$.

Transformations of samples upon heating are schematically presented in Fig. 1. Cell parameters and phase compositions for two phase samples have been estimated using linear equation (1), phase fractions were refined from PXRD data (Table 1). Phase composition after annealing (Table 1) is consistent with existing phase diagram. At least the $h c p-\mathrm{Ir}_{0.45} \mathrm{Os}_{0.55}$ sample has metastable nature which can be explained by the nonequilibrium formation of the $h c p$ phase from a single-source precursor. The same phase separation has been observed previously for $h c p-\mathrm{Ir}_{0.50} \mathrm{Os}_{0.50}$ alloy prepared from $\left[\operatorname{Ir}\left(\mathrm{NH}_{3}\right)_{5} \mathrm{Cl}\right]\left[\mathrm{OsBr}_{6}\right]$ in hydrogen atmosphere at $923 \mathrm{~K}$ [22]. Its annealing at $1273 \mathrm{~K}$ during $72 \mathrm{~h}$ results in the formation of a two-phase mixture. Cell parameters and phase composition for $f c c-\mathrm{Ir}_{0.80} \mathrm{Os}_{0.20}$ and $h c p-\mathrm{Ir}_{0.40} \mathrm{Os}_{0.60}$ have not changed during annealing. Importantly, initially two-phase sample $\operatorname{Ir}_{0.65} \mathrm{Os}_{0.45}$ does not transform into $f c c$ single-phase which can be possibly explained by a low diffusion rate across interfaces between separated phases. 


\subsection{Atomic volumes of Ir-Os alloys: Pressure dependence}

Room temperature compressibility curves for pure metals as well as for solid solutions (except $f c c-\operatorname{Ir}_{0.80} \mathrm{Os}_{0.20}$ ) show no pressure-induced phase transitions and can be fitted using the third-order Birch-Murnaghan equation of state $\left(\mathrm{BM}-\mathrm{E}\right.$ SS) which includes three parameters $-V_{0}$ (specific volume at ambient pressure), $B_{0}$ (bulk modulus), and $B_{0}{ }^{\prime}$ (pressure derivative of bulk modulus). The data have been analysed up to 20 for $h c p-\operatorname{Ir}_{0.40} \mathrm{Os}_{0.60}$ alloy, up to 15 for $h c p-\operatorname{Ir}_{0.20} \mathrm{Os}_{0.80}, 32$ for $h c p-\operatorname{Ir}_{0.55} \mathrm{Os}_{0.45}$, and up to $55 \mathrm{GPa}$ for $f c c-\mathrm{Ir}_{0.80} \mathrm{Os}_{0.20}$ (Fig. 5 and 6). Due to the limited pressure range covered in the current study we have to restrict $B_{0}$ to 4 , and to fit the compressibility curves with second order BM-EoS. The constraint seems to be also reasonable for pure Os and Ir while the best fits with an acceptable minimum between observed and calculated pressures for compressibility data obtained for $B_{0}$ equal or close to 4 , as well as finite strain theory suggests that this value should be close to 4 in stiff materials [33].

Since the cell volumes at ambient pressure were determined with nearly the same experimental uncertainties as for high-pressure data points, the ambient pressure volumes were included in the fitting with EoS-Fit 5.2 software [34]. In all cases, $V_{0}$ values obtained from the fitted compressibility curves and measured directly at ambient conditions were almost indistinguishable (Table 3). 
Bulk moduli, $B_{0}(\mathrm{GPa})$, of Ir-Os alloys appeared between those of pure Ir and Os [4, 7, 8, 33-35] (Table 3 and Fig. 5). As have been mentioned above, data on bulk modulus of pure Os are rather controversial $[7,8,37,38]$. Reported values vary from $395 \mathrm{GPa}$ to $462 \mathrm{GPa}$ i.e. according to Ref. 35 Os is even less compressible than diamond, which has $B_{0}=443(2) \mathrm{GPa}$ [39]. According to thermodynamic model developed by Varotsos and Alexopoulos [40], bulk moduli, $B_{0}\left(x_{O s}\right)$, as a function of the atomic fraction of osmium, $x_{\mathrm{Os}}$, can be written using the following equation:

$$
B_{0}\left(x_{O S}\right)=B_{I r}\left[\frac{1+x_{O S}\left(\frac{V_{O S}}{V_{I r}}-1\right)}{1+x_{O S}\left(\frac{B_{I r} V_{O S}}{B_{O S} V_{I r}}-1\right)}\right]
$$

where $\mathrm{B}_{\text {Ir }}$ and $\mathrm{B}_{\mathrm{oS}}(\mathrm{GPa})$ are bulk moduli, and $\mathrm{V}_{\mathrm{Ir}}$ and $\mathrm{V}_{\mathrm{Os}}\left(\AA^{3} \cdot\right.$ atom $\left.{ }^{-1}\right)$ are atomic volumes at ambient pressure of pure Ir and Os correspondently. Using fixed $B_{0}$ for pure Ir equal to 354(6) GPa [4] and atomic volumes for pure Ir and Os as 14.1556 and $13.9825 \AA^{3} \cdot$ atom $^{-1}$ correspondently (Table 3), experimental bulk moduli for alloys can be fitted using Equation 2 (Fig. 6). Experimental $B_{0}$ values for osmium (Table 3) do not fit Equation 2 and can be parameterized to get the best fit within the dataset as 442(2) GPa. As both, Os and Ir, show controversial bulk moduli, further precise studies should be performed to improve their EoS at room and high-temperatures. Fitting of the bulk moduli dependence with variable $B_{0}$ for pure Ir and Os gives close values 354(2) and 442(4) respectively. Both fitted $B_{0}$ for pure osmium are slightly smaller in comparison with diamond. Our analysis shows that bulk moduli for Ir-Os alloys can be explained using 
thermodynamic model developed by Varotsos [40] and applied for various metallic (see i.e. [41]) and salt binary systems [42]. The model is based on the approximation that the molar volume of an alloy depends linearly on the composition, which interconnects the point defect parameters in alloys and their bulk moduli [42].

The compressibility of $f c c-\mathrm{Ir}_{0.80} \mathrm{Os}_{0.20}$ has been measured up to $55 \mathrm{GPa}$. Material retains $f c c$ structure up to the highest pressure reached, but there is an obvious change in the compressibility above $20 \mathrm{GPa}$ (Fig. 7). Below $20 \mathrm{GPa}$ the fitted values of $B_{0}=368(4) \mathrm{GPa}, V_{0} / Z=14.09(1) \AA^{3} \cdot$ atom $^{-1}$ and above $-B_{0}=$ 484(7) $\mathrm{GPa}, V_{0} / Z=13.98(1) \AA^{3} \cdot$ atom $^{-1}$. Fitting the whole data range (from ambient pressure to $55 \mathrm{GPa}$ ) gives unreasonably high bulk modulus $B_{0}=446(5)$ GPa with $V_{0} / Z=14.04(1) \AA^{3} \cdot$ atom $^{-1}$ and relatively large deviations from experimental points at the pressure about 10-25 GPa and above $45 \mathrm{GPa}$. This observation may point on isostructural transition at about $20 \mathrm{GPa}$, but confirmation of this hypothesis requires further experimental and theoretical investigations.

Silicone oil has been used as a pressure-transmitting medium, which can be non-hydrostatic at high pressure. Comparative studies [43, 45] for various transmitting media such as helium, silicone oil and methanol:ethanol mixture for compressions at room temperature reveal reasonable results for various inorganic and metallic compounds such as $\mathrm{BaSO}_{4}$ up to $48 \mathrm{GPa}$ [45], Dy up to $87 \mathrm{GPa}$ [46], Am up to $100 \mathrm{GPa}[47,48] \mathrm{U}$ up to $100 \mathrm{GPa}$ [49], and Pa up to 
$130 \mathrm{GPa}$ [50] without appearance of any pronounced specialties in their compressibility curves. Such findings make possible a usage of silicone oil as pressure-compressing medium as it requires no special sample-loading equipment [43]. To exclude errors in pressure measurement due to the pressure inhomogenity and gradient, gold calibrant was placed next to the sample and structural parameters were refined from two-phase scans which include both, sample and gold calibrant (see Fig. 2). Parallel measurements in different regions of the sample give comparable pressure and structural parameters as well as diffraction intensity distributes uniformly along diffraction rings (see Fig. 2 , inset) up to $55 \mathrm{GPa}$ without any visible signs characteristic for texturing and mechanical stress in the sample. At the same time, any indication of radiation induced decomposition of silicone oil or reaction between oil and samples were not observed. Nevertheless, further experiments using inert gases such as $\mathrm{He}$ or $\mathrm{Ne}$ as pressure-transmitting media are needed to confirm high-pressure behaviour of alloys above $20 \mathrm{GPa}$.

\section{Summary and conclusions}

Decomposition of single-source precursors can be used for the preparation not only thermodynamically stable multicomponent alloys under mild conditions but also metastable phases such as $h c p-\mathrm{Ir}_{0.50} \mathrm{Os}_{0.50}$ alloy. Further annealing of the metastable phases results in the relaxation to the stable state, which conforms 
with existing equilibrium phase diagram. Synthesis and annealing can be performed in a reasonable time scale which makes the single-source precursors strategy suitable for fundamental research and industrial applications. Cold compression of $f c c-\operatorname{Ir}_{0.80} \mathrm{Os}_{0.20}, h c p-\operatorname{Ir}_{0.55} \mathrm{Os}_{0.45}, h c p-\operatorname{Ir}_{0.40} \mathrm{Os}_{0.60}, h c p-\operatorname{Ir}_{0.20} \mathrm{Os}_{0.80}$ and metastable at ambient conditions $h c p-\mathrm{Ir}_{0.45} \mathrm{Os}_{0.55}$ up to $30 \mathrm{GPa}$ does not reveal any structural transformations. Their atomic volumes measured at ambient conditions using powder x-ray diffraction follow nearly linear dependence as a function of composition. Bulk moduli fitted with the secondorder Birch-Murnaghan equation of state also depend on the composition of alloys and increase with increasing osmium content. The concentration dependence of bulk moduli for $\mathrm{Ir}-\mathrm{Os}$ alloys can be described by a thermodynamic model developed by Varotsos [40], which interconnects the point defect parameters in alloys and their bulk moduli. Compressibility curve of $f c c-\operatorname{Ir}_{0.80} \mathrm{Os}_{0.20}$ measured up to $55 \mathrm{GPa}$ cannot be fitted with a single equation of state indicating possible changes in properties of this alloy at about $20 \mathrm{GPa}$. Further experiments with various compositions for both $f c c$ and $h c p$ alloys should be performed at pressure above $20 \mathrm{GPa}$ to prove presence of any transitions at about $20 \mathrm{GPa}$. Theoretical calculations of electronic structure of alloys under pressure may support our findings as well as direct spectroscopical investigation of their electronic states under pressure above and below $20 \mathrm{GPa}$. 


\section{Acknowledgments}

The authors thank European Synchrotron Radiation Facility (ESRF) for providing us measurement time and support. Financial support by German Science Foundation (DFG), German Ministry of Science and Education (BMBF) as well as Research Council of Norway (Forskingsrådet, FRINATEK) is greatly appreciated. Portions of this work were performed at GeoSoilEnviroCARS (Sector 13), Advanced Photon Source (APS), Argonne National Laboratory. GeoSoilEnviroCARS is supported by the National Science Foundation - Earth Sciences (EAR-1128799) and Department of Energy- GeoSciences (DE-FG0294ER14466). Use of the Advanced Photon Source was supported by the U. S. Department of Energy, Office of Science, Office of Basic Energy Sciences, under Contract No. DE-AC02-06CH11357. The authors would also like to thank the Referees for many helpful suggestions without which this paper would be much less complete. 


\section{References}

[1] E.Y. Tonkov, E.G. Ponyatovsky, Phase transformations of elements under high pressure, CRC Press LLC, 377 p. (2005).

[2] M.I. McMahon, R.J. Nelmes, High-pressure structures and phase transformations in elemental metals Chem. Soc. Rev. 35 (2006), 943-963. DOI: 10.1039/B517777B

[3] L. Dubrovinsky, N. Dubrovinskaia, V.B. Prakapenka, A.M. Abakumov, Implementation of micro-ball nanodiamond anvils for high-pressure studies above 6 Mbar, Nat. Commun. 3(1163) (2012), 1-7. DOI: 10.1038/ncomms2160.

[4] Y. Cerenius, L. Dubrovinsky, Compressibility measurements on iridium, J. Alloys Compd, 306(1-2) (2000), 26-29. DOI: 10.1016/S0925-8388(00)00767-2

[5] S. Grussendorff, N. Chetty, H. Dreysse, Theoretical studies of iridium under pressure, J. Phys.: Condens. Matter, 15 (2003), 4127-4134.

[6] B.K. Godwal, J. Yan, S.M. Clark, R. Jeanloz, High-pressure behavior of osmium: An analog for iron in Earth's core, J. Appl. Phys., 111 (2012), 112608. DOI: $10.1063 / 1.4726203$

[7] F. Occelli, D.L. Farber, J. Badro, C.M. Aracne, D.M. Teter, M. Hanfland, B. Canny, B. Couzinet, Experimental evidence for a high-pressure isostructural phase transition in osmium, Phys. Rev. Lett., 93(9) (2004), 095502. DOI: http://dx.doi.org/10.1103/PhysRevLett.93.095502 
[8] T. Kenichi, Bulk modulus of osmium: High-pressure powder x-ray diffraction experiments under quasihydrostatic conditions, Phys. Rev. B, 70 (2004), 012101. DOI: http://dx.doi.org/10.1103/PhysRevB.70.012101

[9] L.D. Blackburn, L. Kaufman, M. Cohen, Phase Transformations in IronRuthenium alloys under high pressure, Acta Metallurgica, 13 (1965), 533-541. DOI: 10.1016/0001-6160(65)90104-5

[10] I. Halevy, S. Salhov, M.L. Winterrose, A. Broide, A.F. Yue, A. Robin, O. Yeheskel, J. Hu, I. Yaar, High pressure study and electronic structure of the super-alloy HfIr $_{3}$, J. Phys.: Conf. Ser., 215(1) (2010), 012012. doi:10.1088/1742-6596/215/1/012012

[11] G. Rakhtsaum, Platinum Alloys: A Selective Review of the Available $\begin{array}{lllll}\text { Literature, } & \text { Platinum } & \text { Met. } & \text { Rev., } & \text { 57(3) (2013), }\end{array}$ http://dx.doi.org/10.1595/147106713X668596

[12] G.L.W. Hart, S. Curtarolo, Th.B. Massalski, O. Levy, A high-throughput ab initio review of platinum-group alloy systems, Phys. Rev. X, (2013) http://arxiv.org/pdf/1308.4357.pdf

[13] O. Degtyareva, V. F. Degtyareva, F. Porsch, W.B. Holzapfel, Phase transitions under high pressure in binary Sn alloys (with In, Hg and Ga), J. Phys.: Condens. Matter, 14 (2002), 389. doi:10.1088/0953-8984/14/3/309

[14] R.D. Reiswig, J.M. Dickinson, The Osmium-Iridium Equilibrium Diagram, Trans. Metall. Soc. AIME, 230 (1964) 469-472. 
[15] H. Okamoto, The Ir-Os (Iridium-Osmium) System, J. Phase Equilib., 15 (1994), 55-57. DOI: 10.1007/BF02667683

[16] H.C. Vacher, C.J. Bechtoldt, E. Maxwell, Structure of Some IridiumOsmium Alloys, J. Metals, 200(1) (1954), 80-82.

[17] T. H. Gebali, E B. T. Matthias V. B. Compton, E. Corenzwit, D G. W. Hull JR., Superconductivity of Solid Solutions of Noble Metals, Phys. Rev. 129(1) (1963), 182-183. DOI: http://dx.doi.org/10.1103/PhysRev.129.182

[18] J.M. Bird, W.A. Bassett, Evidence of a Deep Mantle History in Terrestrial Osmium-Iridium-Ruthenium Alloys, J. Geophys. Res., 85 (1980), 5461-5470. DOI: 10.1029/JB085iB10p05461

[19] D.C. Harris, L.J. Cabri, Nomenclature of platinum-group-element alloys: review and revision, Can. Miner., 29 (1991), 231-237.

[20] R.O.C. Fonseca, V. Laurenz, G. Mallmann, A. Luguet, N. Hoehne, K.P. Jochum, New constraints on the genesis and long-term stability of Os-rich alloys in the Earth's mantle, Geochim. Cosmochim. Acta, 87 (2012), 227-242. DOI: 10.1016/j.gca.2012.04.002

[21] M.B. Weinberger, S.H. Tolbert, A. Kavner, Osmium Metal Studied under High Pressure and Nonhydrostatic Stress, Phys. Rev. Lett., 100 (2008), 045506. DOI: http://dx.doi.org/10.1103/PhysRevLett.100.045506

[22] I.V. Korolkov, S.A. Gromilov, K.V. Yusenko, I.A. Baidina, S.V. Korenev, Crystal structure of the $\left[\operatorname{Ir}\left(\mathrm{NH}_{3}\right)_{5} \mathrm{Cl}\right]_{2}\left[\mathrm{OsCl}_{6}\right] \mathrm{Cl}_{2}$. Crystal analysis of the $\mathrm{Ir}-\mathrm{Os}$ 
metallic system, J. Struct. Chem., 46(6) (2005), 1052-1059. DOI: $10.1007 / \mathrm{s} 10947-006-0241-8$

[23] I.V. Korolkov, A.I. Gubanov, K.V. Yusenko, I.A. Baidina, S.A. Gromilov, Synthesis of non-equilibrium $\mathrm{Pt}_{x} \mathrm{Os}_{1-x}$ solid solutions. Crystal structure of $\left[\operatorname{Pt}\left(\mathrm{NH}_{3}\right)_{4}\right]\left[\mathrm{OsCl}_{6}\right], \quad$ J. $\quad$ Struct. $\quad$ Chem., $\quad 48(3) \quad$ (2007), 486-493. DOI: 10.1007/s10947-007-0073-1

[24] I. Kantor, V. Prakapenka, A. Kantor, P. Dera, A. Kurnosov, S. Sinogeikin, N. Dubrovinskaia, and L. Dubrovinsky, BX90: A new diamond anvil cell design for X-ray diffraction and optical Measurements, Rev. Sci. Instrum., 83 (2012), 125102. http://dx.doi.org/10.1063/1.4768541

[25] Y. Fei, A. Ricolleau, M. Frank, G. Shen, V. Prakapenka, Toward an internally consistent pressure scale, PNAS, 104(22) (2007), 9182-9186. DOI: 10.1073/pnas.0609013104

[26] A. P. Hammersley, S. O. Svensson, M. Hanfland, A. N. Fitch, and D. Häusermann, Two-Dimensional Detector Software: From Real Detector to Idealised Image or Two-Theta Scan, High Press. Res., 14 (1996), 235-248. DOI: $10.1080 / 08957959608201408$

[27] V. Petricheck, M. Duscheck, L. Palatinus, Jana2006. The crystallographic computing system. -Institute of Physics. - Praha, Czech Republic. - 2006; http://www-xray.fzu.cz/jana/jana.html [28] PDF-2 Release 2012 (Database), ed. S. Kabekkodu, International Centre for Diffraction Data, Newtown Square, PA, USA (2012). 
[29] R.S. Rudman, Lattice parameters of some h.c.p. binary alloys of rhenium and osmium: Re-W, Re-Ir, Re-Pt; Os-Ir, Os-Pt, J. Less-Common Metals, 12(1) (1967), 79-81. DOI: 10.1016/0022-5088(67)90075-6

[30] Zen E-an, Validity of "Vegard's Law”, Am. Mineral., 41 (1956), 523-524.

[31] A. R. Denton, N. W. Ashcroft, Phys. Rev. A, 43 (1991), 3161. DOI: http://dx.doi.org/10.1103/PhysRevA.43.3161

[32] W. B. Pearson, The Crystal Chemistry and Physics of Metals and Alloys, Wiley-Interscience, New York, USA, 1972, 30, 31.

[33] J.-P. Poirier, Introduction to the physics of the Earth's interior, Cambridge University Press (Virtual Publishing), Edition 2, 326 p. (2003).

[34] R.J. Angel, Equations of State. In Hazen, R.M., Downs, R.T. (Eds.), Highpressure, high-temperature crystal chemistry. Reviews in Mineralogy and Geochemistry, 41 (2001), 35-60. http://www.rossangel.com/

[35] A.F. Goncharov, J.C. Crowhurst, J.K. Dewhurst, S. Sharma, Ch. Sanloup, E. Gregoryanz, N. Guignot, and M. Mezouar, Thermal equation of state of cubic boron nitride: Implications for a high-temperature pressure scale, Phys. Rev. B, 75 (2007) 224114. DOI: 10.1103/PhysRevB.75.224114

[36] A. F. Young, C. Sanloup, E. Gregoryanz, S. Scandolo, R. J. Hemley, and H.-K. Mao, Synthesis of novel transitions metal nitrides $\operatorname{IrN}_{2}$ and $\mathrm{OsN}_{2}$, Phys.

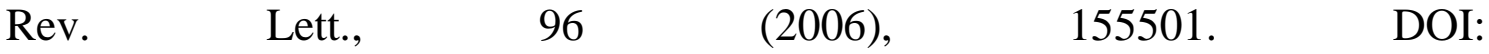
http://dx.doi.org/10.1103/PhysRevLett.96.155501 
[37] H. Cynn, J. E. Klepeis, C.-S. Yoo, D. A. Young, Osmium has the lowest experimentally determined compressibility, Phys. Rev. Lett., 88 (2002), 135701. DOI: http://dx.doi.org/10.1103/PhysRevLett.88.135701

[38] A. Rubio-Ponce, D. Olgu'in, R. de Coss, Ab-initio study of the structural and electronic properties of osmium under high pressure, J Phys.: Conference Series, 410 (2013), 012049. DOI: 10.1088/1742-6596/410/1/012049.

[39] F. Occelli, P. Loubeyre, R. Le Toullec, Properties of diamond under hydrostatic pressures up to $140 \mathrm{GPa}$, Nat. Mater. 2 (2003), 151. DOI: $10.1038 / \mathrm{nmat} 831$

[40] P. Varotsos, K. Alexopoulos, In Thermodynamics of Point Defects and Their Relation with Bulk Properties Series, Defects in Solids, Amelinckx, S., Gevers, R., Nihoul, J., Eds.; North-Holland Publ. Co.: Amsterdam, 1986; pp 325-347 and pp 156-158.

[41] Chonghe, P, Wu, Correlation of Bulk Modulus and the Constituent Element Properties of Binary Intermetallic Compounds Chem. Mater., 13 (2001), 4642. DOI: $10.1021 / \mathrm{cm} 0104203$

[42] P. Varotsos, K. Alexopoulos, On the Temperature Variation of the Bulk Modulus of Mixed Alkali Halides, Phys. Status Sol. B, 99 (1980), K93. DOI: 10.1002/pssb.2220990243 
[43] Y. Shen, R.S. Kumar, M. Pravica, M.F. Nicol, Characteristics of Silicone Fluid as a Pressure Transmitting Medium in diamond anvil cells, Rew. Scient. Instr., 75 (2004), 4450-4454. DOI: 10.1063/1.1786355

[44] S. Klotz, J-C Chervin, P Munsch, G Le Marchand, Hydrostatic limits of 11 pressure transmitting media, J. Phys. D: Appl. Phys., 42 (2009), 075413. DOI:10.1088/0022-3727/42/7/075413

[45] D. Santamaria-Perez, L. Gracia, G. Garbarino, A. Beltran, R. Chulia-Jordan, O. Gomis, D. Errandonea, Ch. Ferrer-Roca, D. Martinez-Garcia, A. Segura, High-pressure study of the behavior of mineral barite by x-ray diffraction, Phys. $\begin{array}{lllll}\text { Rev. } & \text { B., } & 84 & \text { (2011), } & \text { 054102. }\end{array}$ http://dx.doi.org/10.1103/PhysRevB.84.054102

[46] Y.R. Shen, R.S. Kumar, A.L. Cornelius, M.F. Nicol, High-pressure structural studies of dysprosium using angle dispersive x-ray diffraction, Phys.

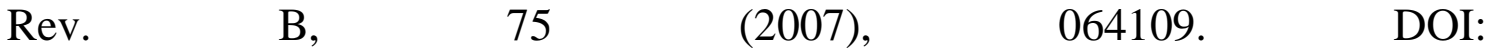
http://dx.doi.org/10.1103/PhysRevB.75.064109

[47] S. Heathman, R. G. Haire, T. Le Bihan, A. Lindbaum, K. Litfin, Y. Méresse, and H. Libotte, Pressure Induces Major Changes in the Nature of Americium's 5f Electrons, Phys. Rev. Lett., 85 (2000), 2961. DOI: http://dx.doi.org/10.1103/PhysRevLett.85.2961

[48] A. Lindbaum, S. Heathman, K. Litfin, Y. Meresse, R.G. Haire, T. Le Bihan, H. Libotte, High-pressure studies of americium metal: Insights into its position 
in the actinide series, Phys. Rev. B, 63 (2001), 214101. DOI: http://dx.doi.org/10.1103/PhysRevB.63.214101

[49] T. Le Bihan, S. Heathman, M. Idiri, G. H. Lander, J. M. Wills, A. C. Lawson, A. Lindbaum, Structural behavior of $\alpha$-uranium with pressures to 100 GPa, Phys. Rev. B, 67 (2003), 134102. DOI: http://dx.doi.org/10.1103/PhysRevB.67.134102

[50] R. G. Haire, S. Heathman, M. Idiri, T. Le Bihan, A. Lindbaum, J. Rebizant, Pressure-induced changes in protactinium metal: Importance to actinide-metal bonding concepts, Phys. Rev. B, 67 (2003), 134101. DOI: http://dx.doi.org/10.1103/PhysRevB.67.134101 
Figure 1. Experimental Ir-Os binary phase diagram [15]. Squares and hexagons correspond to $f c c$ and $h c p$ alloys synthesized in the current work; two-phase samples are shown by circles; arrows indicate transformations upon heating.

Figure 2. Least-square fit for $h c p-\operatorname{Ir}_{0.20} \mathrm{Os}_{0.80}$ with gold as internal standard at 28.6(5) GPa $(\lambda=0.4145 \AA)$. Experimental data-points are shown as circles, refined profile - as solid line, difference curve is shown at the bottom. Inset shows radial sweep of 2D image.

Figure 3. SEM images of $\left(\mathrm{NH}_{4}\right)_{2}\left[\mathrm{Ir}_{0.65} \mathrm{Os}_{0.35} \mathrm{Cl}_{6}\right]$ precursor (a) and its decomposition product (b and c).

Figure 4. Concentration dependence of atomic volumes of $\mathrm{Ir}-\mathrm{Os}$ alloys and corresponding linear fit. Squares and hexagons correspond to $f c c$ and $h c p$ alloys respectively. Literature values $[22,28,29]$ are shown as open symbols and filled symbols are for the values obtained in the current study.

Figure 5. Relative volume compressions for Ir [4], Os [7] (dashed lines), and Ir-Os alloys (solid lines).

Figure 6. A composition dependence of bulk moduli for pure Ir, Os and Ir-Os alloys. Line corresponds to $B_{0}\left(x_{\mathrm{Os}}\right)$ dependence according to Equation 2 with fixed $B_{0}=354 \mathrm{GPa}$ for Ir [4] and fitted $B_{0}$ for Os (fitting gives $B_{0}=442(2)$ ). Star shows bulk modulus for diamond [39].

Figure 7. Pressure dependence of atomic volume for $f c c-\mathrm{Ir}_{0.80} \mathrm{Os}_{0.20}$ sample. Lines show the second-order BM-EoS fits for the whole pressure interval (orange), below $20 \mathrm{GPa}$ (blue) and above $20 \mathrm{GPa}$ (green). 

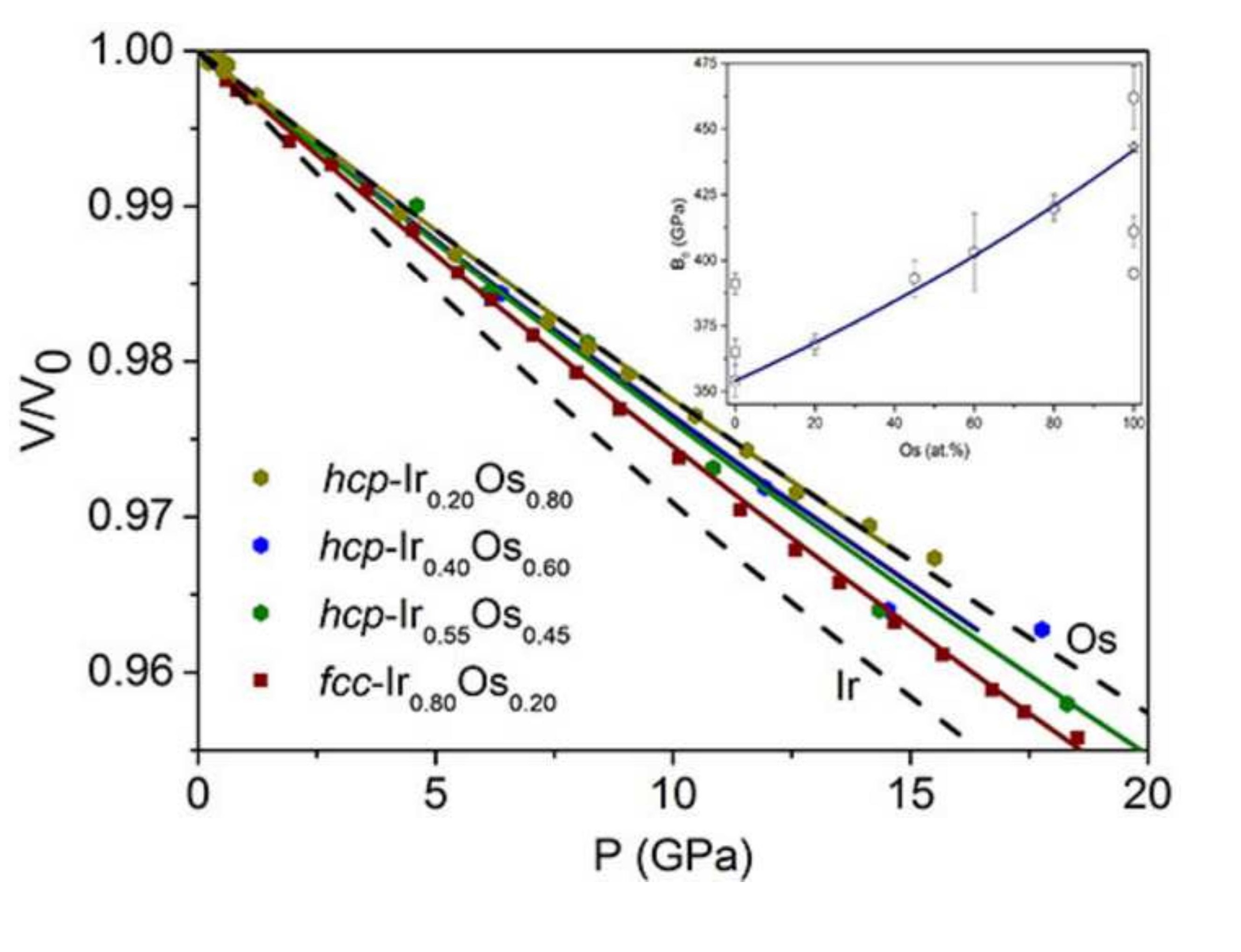
Table 1. Crystallographic data for Ir-Os samples at room temperature and ambient pressure (synthesized at $873 \mathrm{~K}$ and annealed at $1273 \mathrm{~K}$ ).

\begin{tabular}{|c|c|c|c|c|c|c|c|c|c|c|}
\hline \multicolumn{6}{|c|}{ As synthetized $(873 \mathrm{~K}, 0.5 \mathrm{~h})$} & \multicolumn{5}{|c|}{ Annealed (1273 K, 40 h) } \\
\hline $\begin{array}{l}\text { Nominal composition } \\
\text { (According to EDX) }\end{array}$ & $a, \AA$ & $c, \AA$ & $c / a$ & Space group & $\mathrm{V} / \mathrm{Z}, \AA^{3} \cdot$ atom $^{-1}$ & $a, \AA$ & $c, \AA$ & $V / Z, \AA^{3} \cdot$ atom $^{-1}$ & Space group & Composition $^{\mathrm{a}}$ \\
\hline $\begin{array}{l}f c c-\mathrm{Ir}_{0.80} \mathrm{Os}_{0.20} \\
\left(\mathrm{Ir}_{0.79(2)} \mathrm{Os}_{0.21(2)}\right)\end{array}$ & $3.836(2)$ & $3.836(2)$ & - & $F m 3 m$ & $14.112(2)$ & $3,836(2)$ & $3,836(2)$ & $14.112(2)$ & $F m 3 m$ & $f c c-\mathrm{Ir}_{0.80} \mathrm{Os}_{0.20}$ \\
\hline $\mathrm{Ir}_{0.65} \mathrm{Os}_{0.35}{ }^{\mathrm{b}}$ & $3.828(2)$ & $3.828(2)$ & - & $F m 3 m$ & $14.125(2)$ & $3.836(2)$ & $3.836(2)$ & 14.112(2) & $F m 3 m$ & $90 \% f c c-\mathrm{Ir}_{0.26} \mathrm{Os}_{0.74}$ \\
\hline$\left(\mathrm{Ir}_{0.65(2)} \mathrm{Os}_{0.35(2)}\right)$ & $2.729(2)$ & $4.380(3)$ & $1.605(2)$ & $P 6_{3} \mathrm{Vmmc}$ & $14.023(2)$ & $2.724(2)$ & $4.370(3)$ & $14.026(2)$ & $P 6_{3} \backslash m m c$ & $10 \% h c p-\mathrm{Ir}_{0.72} \mathrm{Os}_{0.18}$ \\
\hline $\begin{array}{l}h c p-\mathrm{Ir}_{0.55} \mathrm{Os}_{0.45} \\
\left(\mathrm{Ir}_{0.56(2)} \mathrm{Os}_{0.44(2)}\right)\end{array}$ & $2.728(2)$ & $4.373(3)$ & $1.603(2)$ & $P 6_{3} \backslash m m c$ & $14.092(2)$ & $\begin{array}{l}3.836(2) \\
2.724(2)\end{array}$ & $\begin{array}{l}3.836(2) \\
4.370(3)\end{array}$ & $\begin{array}{l}14.112(2) \\
14.041(2)\end{array}$ & $\begin{array}{c}F m 3 m \\
P 6_{3} \backslash m m c\end{array}$ & $\begin{array}{l}90 \% f c c-\mathrm{Ir}_{0.75} \mathrm{Os}_{0.25} \\
10 \% h c p-\mathrm{Ir}_{0.36} \mathrm{Os}_{0.64}\end{array}$ \\
\hline $\begin{array}{c}h c p-\mathrm{Ir}_{0.50} \mathrm{Os}_{0.50}{ }^{\mathrm{c}} \\
(-)\end{array}$ & $2.729(2)$ & $4.361(3)$ & $1.598(2)$ & $\mathrm{Pb}_{3} \mathrm{Vmmc}$ & $14.058(2)$ & $\begin{array}{l}3.836(2) \\
2.725(2)\end{array}$ & $\begin{array}{l}3.836(2) \\
4.366(3)\end{array}$ & $\begin{array}{l}1.4112(2) \\
14.040(2)\end{array}$ & $\begin{array}{c}F m 3 m \\
P 6_{3} \backslash m m c\end{array}$ & $\begin{array}{l}68 \% f c c-\mathrm{Ir}_{0.75} \mathrm{Os}_{0.25} \\
32 \% h c p-\mathrm{Ir}_{0.35} \mathrm{Os}_{0.65}\end{array}$ \\
\hline $\begin{array}{l}h c p-\mathrm{Ir}_{0.40} \mathrm{Os}_{0.60} \\
\left(\mathrm{Ir}_{0.41(2)} \mathrm{Os}_{0.59(2)}\right)\end{array}$ & $2.733(2)$ & $4.350(3)$ & $1.592(2)$ & $\mathrm{Pb}_{3} \backslash m m c$ & $14.069(2)$ & $2,731(2)$ & $4,343(3)$ & $14.043(2)$ & $P 6_{3} \backslash m m c$ & $h c p-\mathrm{Ir}_{0.40} \mathrm{Os}_{0.60}$ \\
\hline $\begin{array}{l}h c p-\mathrm{Ir}_{0.20} \mathrm{Os}_{0.80} \\
\left(\mathrm{Ir}_{0.19(2)} \mathrm{Os}_{0.81(2)}\right)\end{array}$ & $2.731(4)$ & $4.329(6)$ & $1.585(2)$ & $P_{3} \mathrm{Vmmc}$ & 13.982(4) & - & - & - & - & - \\
\hline
\end{tabular}

${ }^{\text {a }}$ Phase compositions for two phase samples were estimated from whole-profile Reitveld refinement; elemental compositions for each $f c c$ - and $h c p$-phase were estimated according to linear dependence $(V / Z)=14.157(6)-0.18(1) \bullet x_{\mathrm{Os}}$, where $x_{\mathrm{Os}}$ is atomic fraction of Os in the alloy.

${ }^{\mathrm{b}}$ Two-phase sample: $65 \% f c c-\mathrm{Ir}_{0.26} \mathrm{Os}_{0.74}+35 \% h c p-\mathrm{Ir}_{0.72} \mathrm{Os}_{0.18}$.

${ }^{\mathrm{c}}$ single-phase $h c p-\mathrm{Ir}_{0.50} \mathrm{Os}_{0.50}$ alloy $\left(a=2.729(2), c=4.361(3) \AA\right.$ ) was prepared by the thermal decomposition of $\left[\mathrm{Ir}\left(\mathrm{NH}_{3}\right)_{5} \mathrm{Cl}\right]\left[\mathrm{OsBr}_{6}\right]$ at $973 \mathrm{~K}_{\text {in }}$ hydrogen atmosphere [22]. 
Table 2. Crystallographic data for known alloys in the Ir-Os system.

\begin{tabular}{|c|c|c|c|c|c|c|c|}
\hline Sample & $a, \AA$ & $c, \AA$ & $c / a$ & Space group & $D_{x}, \mathrm{~g} \cdot \mathrm{cm}^{-3}$ & $\mathrm{~V} / \mathrm{Z}, \AA^{3} \cdot$ atom $^{-1}$ & Reference \\
\hline$f c c$-Ir & $3.8400(1)$ & - & - & $F m 3 m$ & $22.560(1)$ & $14.1556(1)$ & [28] \\
\hline$f c c-\mathrm{Ir}_{0.88} \mathrm{Os}_{0.12}$ & $3.84(2)$ & - & - & $F m 3 m$ & $22.52(1)$ & $14.155(60)$ & [28] \\
\hline$f c c-\mathrm{Ir}_{0.80} \mathrm{Os}_{0.20}$ & $3.8558(7)$ & - & - & $F m 3 m$ & $22.574(3)$ & $14.11(4)$ & [29] \\
\hline$f c c-\mathrm{Ir}_{0.75} \mathrm{Os}_{0.25}$ & $3.836(2)$ & - & - & $F m 3 m$ & $22.558(3)$ & $14.11(2)$ & [22] \\
\hline$h c p-\mathrm{Ir}_{0.50} \mathrm{Os}_{0.50}$ & $2.729(2)$ & $4.363(3)$ & $1.599(2)$ & $\mathrm{P}_{3} \backslash \mathrm{Im} \mathrm{mc}$ & $22.565(3)$ & $14.07(2)$ & [22] \\
\hline$h c p-\operatorname{Ir}_{0.35} \mathrm{Os}_{0.65}$ & $2.7361(7)$ & $4.3417(12)$ & $1.587(1)$ & $\mathrm{PG}_{3} \backslash \mathrm{mmc}$ & $22.523(3)$ & $14.07(4)$ & [29] \\
\hline$h c p-\mathrm{Ir}_{0.30} \mathrm{Os}_{0.70}$ & $2.7347(7)$ & $4.3380(12)$ & $1.586(1)$ & $\mathrm{PG}_{3} \backslash \mathrm{Mmc}$ & $22.553(3)$ & $14.05(4)$ & [29] \\
\hline$h c p-\mathrm{Ir}_{0.25} \mathrm{Os}_{0.75}$ & $2.733(2)$ & $4.331(3)$ & $1.585(2)$ & $P 6_{3} \backslash m m c$ & $22.606(3)$ & $14.01(2)$ & [22] \\
\hline
\end{tabular}


Table 3. Fitted parameters for the second-order BM-EoS for compressed Ir-Os binary alloys and pure Ir and Os.

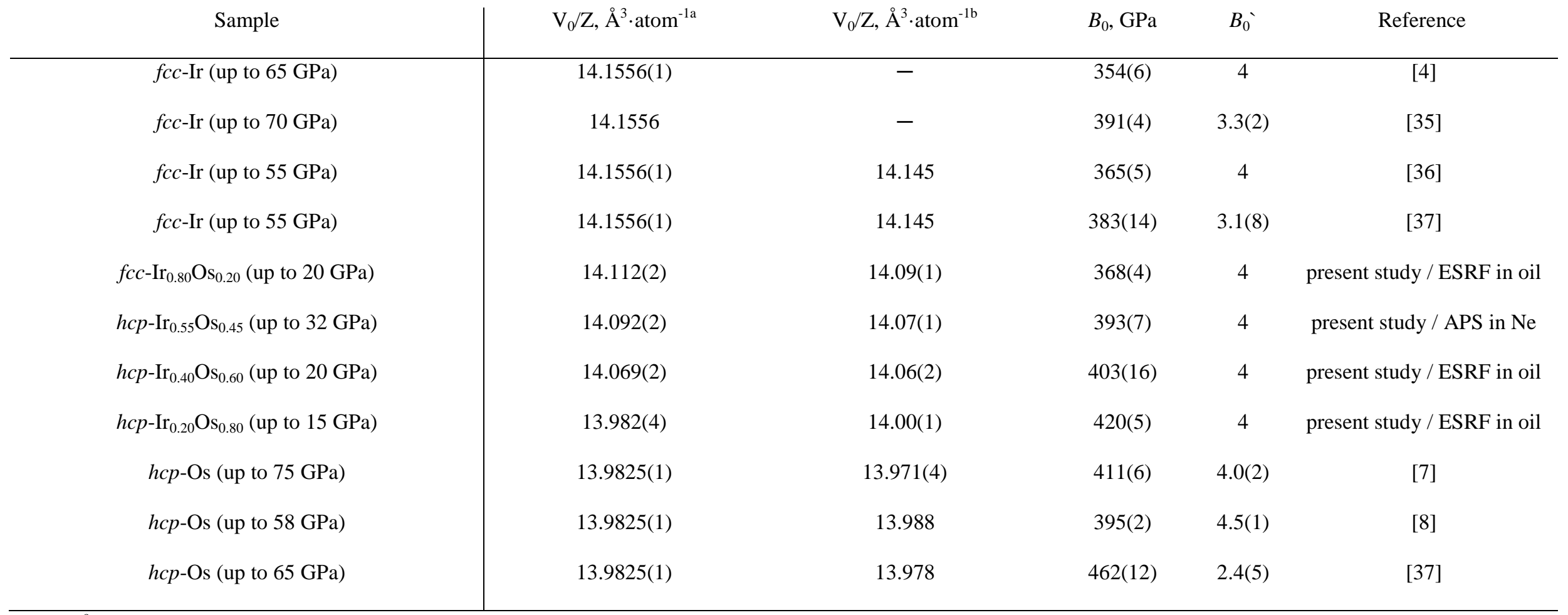

${ }^{a}$ atomic volume refined from PXRD data at ambient conditions;

${ }^{b}$ atomic volume obtained from BM-EoS. 


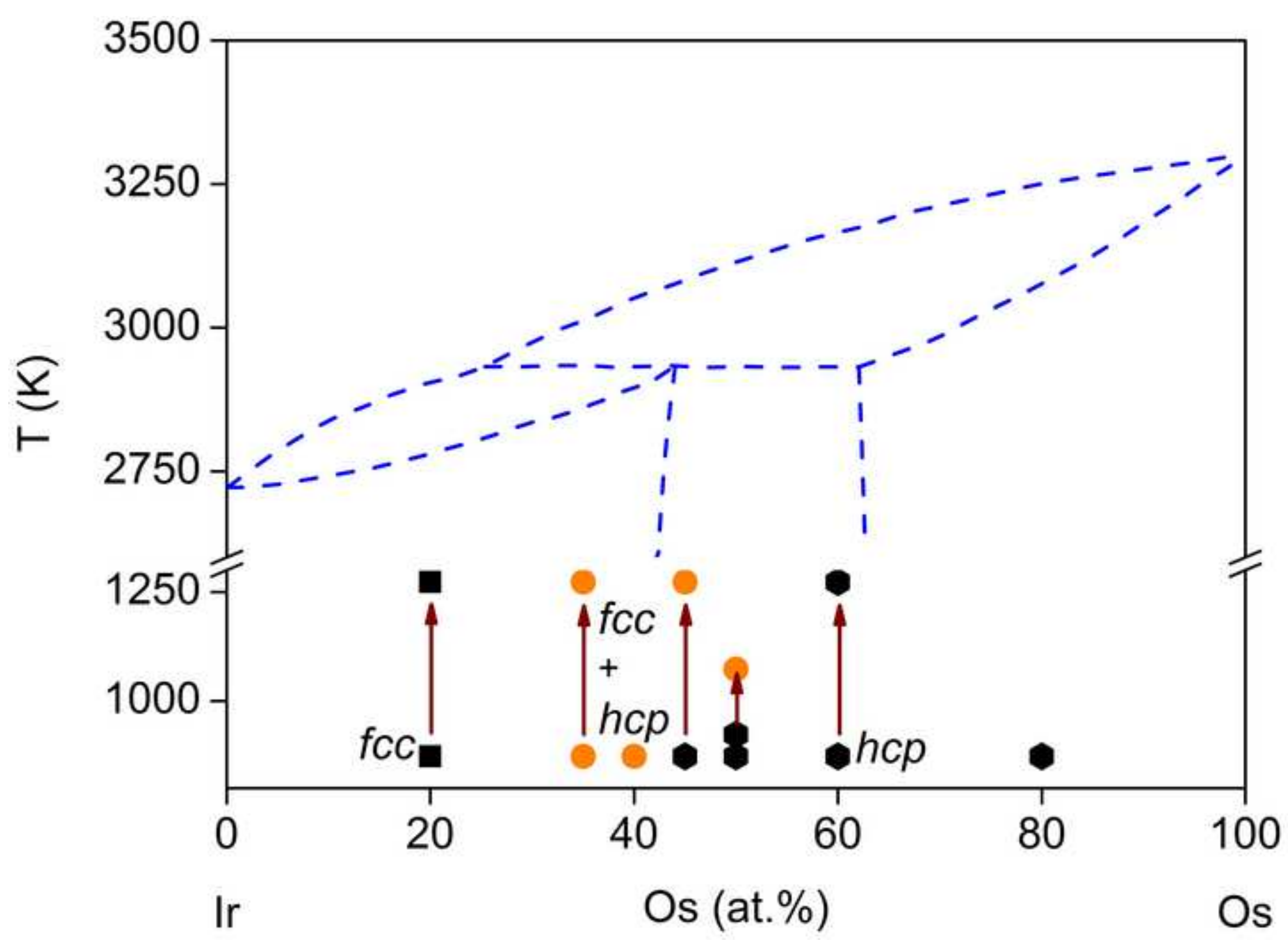




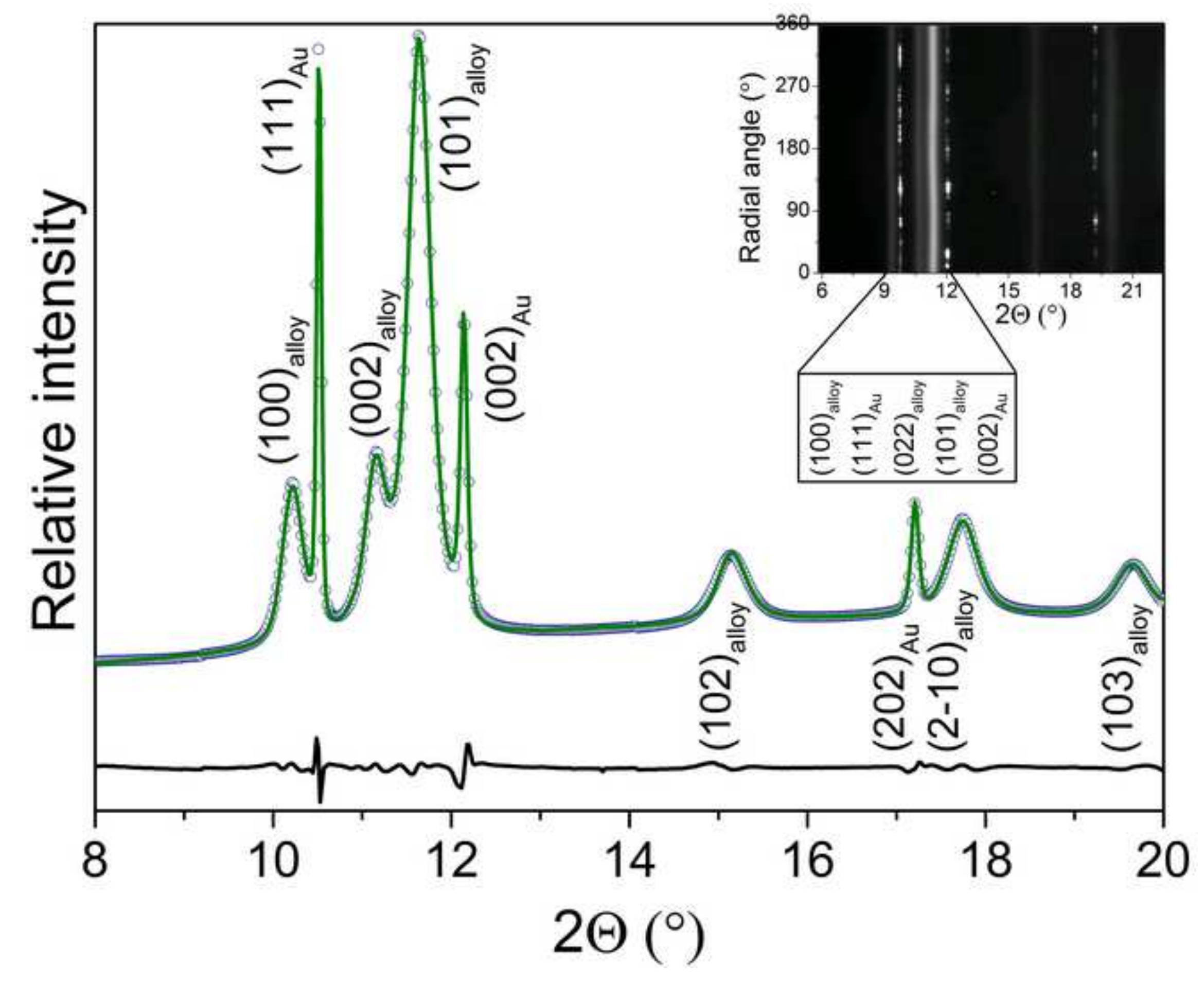



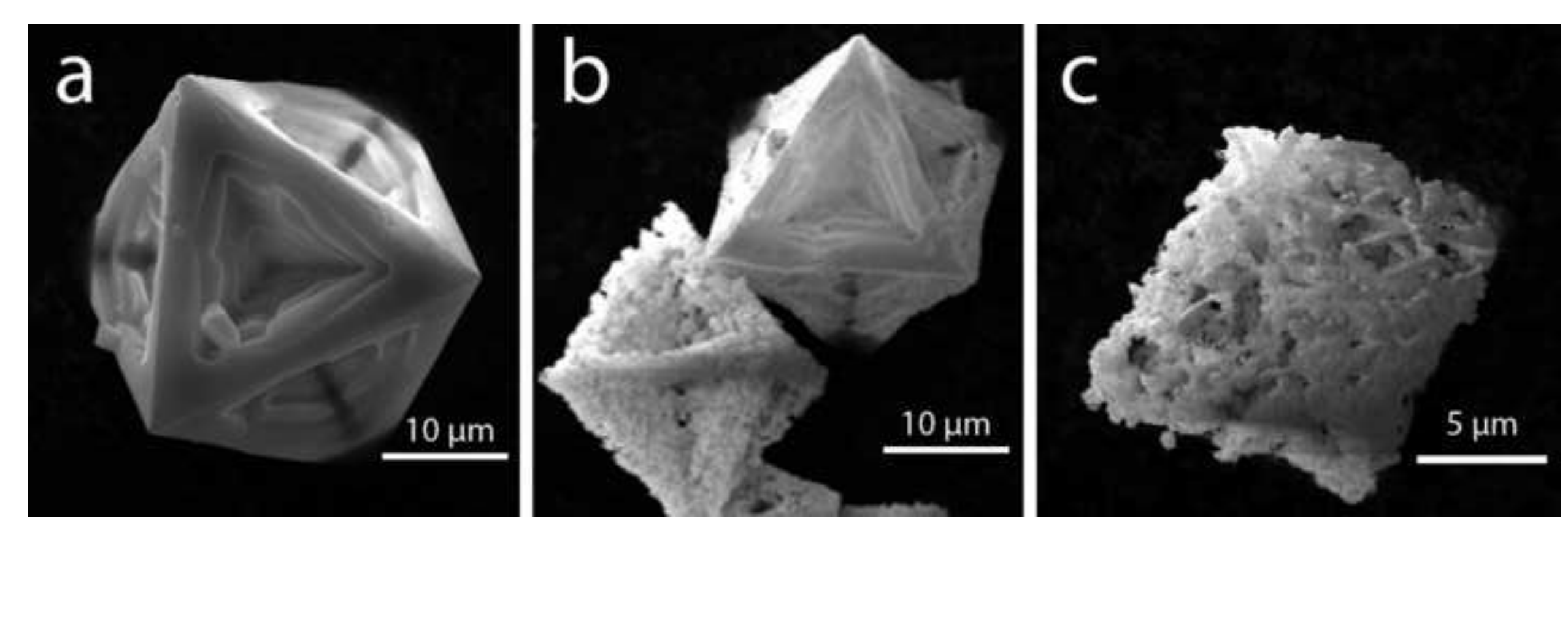


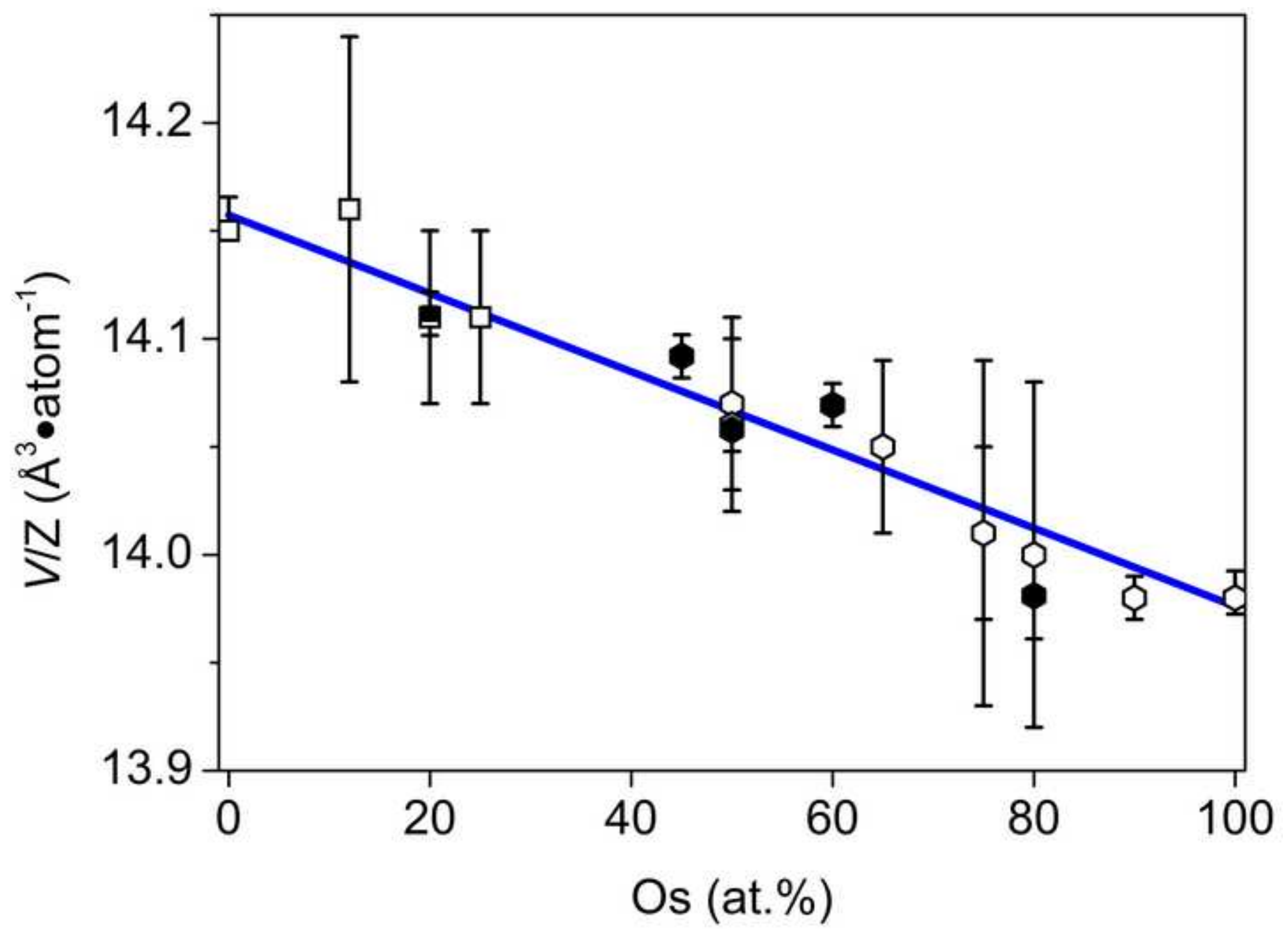




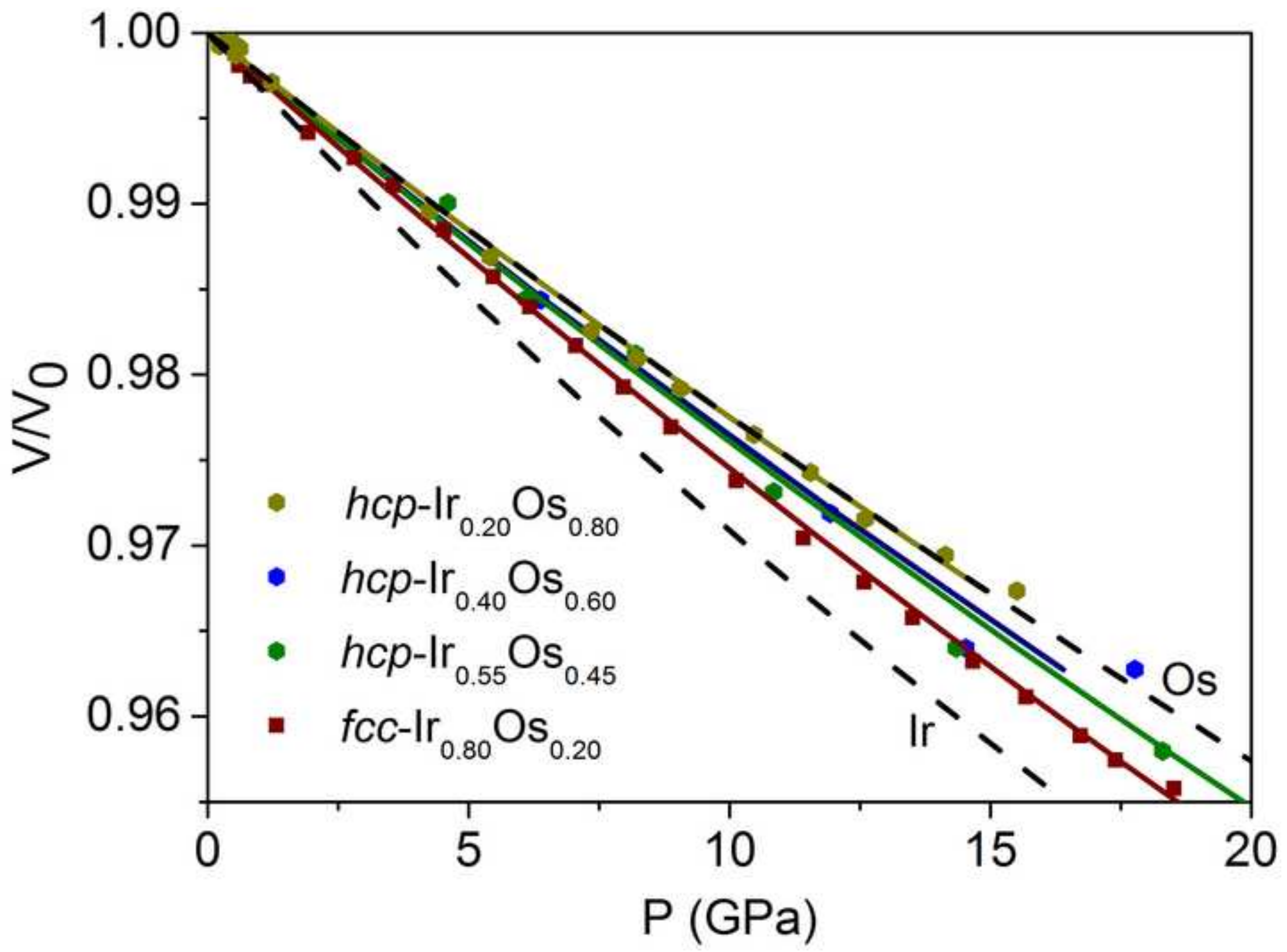




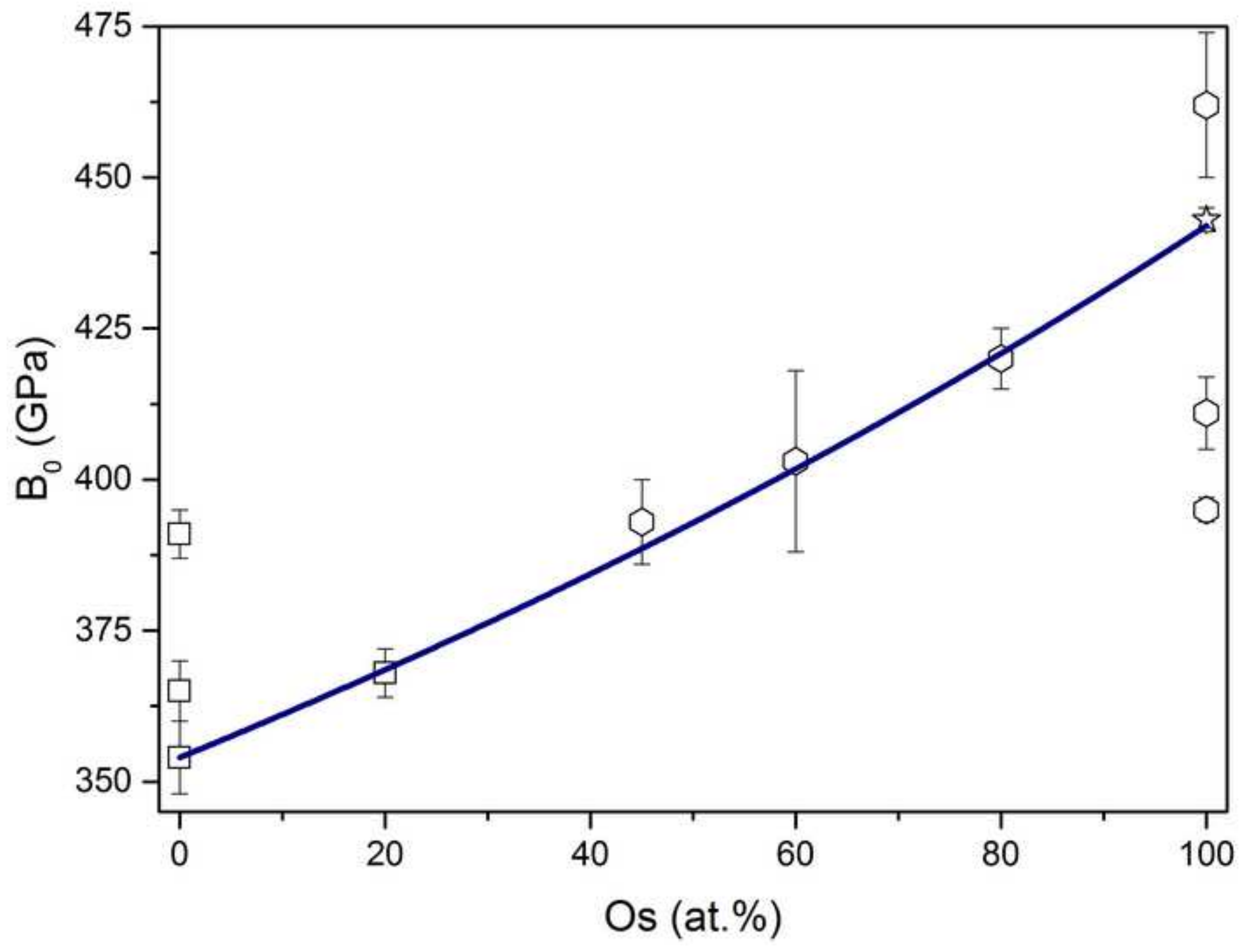




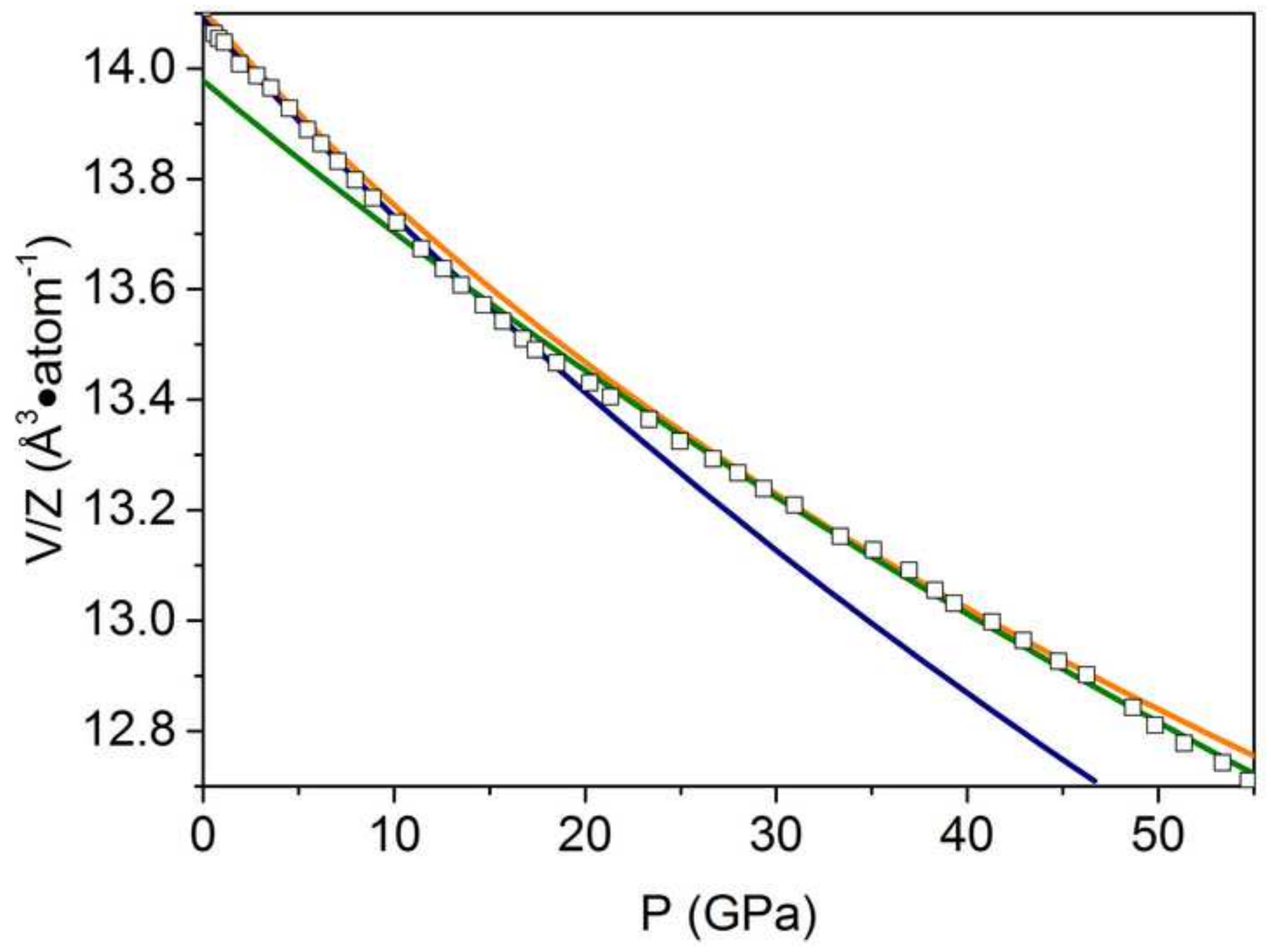

